\title{
Digital innovations as a development driver for regional management and consumer interaction in the post-pandemic period
}

\author{
Diana Yampolskaya*, and Sergey $U$. Chernikov \\ Peoples' Friendship University of Russia, Moscow, Russia
}

\begin{abstract}
The development of enterprises and organizations in the new conditions created by the COVID-19 pandemic raises many problems and sets new challenges. This article examines issues related to the changing operating conditions of regional companies, their use of digital technologies and the development of e-commerce. The relevance of the work is dictated by extensive discussion of these issues in the media and field research to determine the readiness of companies to transition to digital technologies. The need for this transition is apparent. Both positive and negative aspects of the transition to new working conditions have been identified based on the results of a content analysis of open sources of information. Digital technologies enable more flexible and dynamic development of companies, comprehensive services to their customers through the creation of service ecosystems. Electronic commerce is developing rapidly. At the same time, digitalization can divide the team, increase control (and therefore pressure) on personnel, and cause emotional burnout of employees. Consideration of these areas and a set of digitalization tasks is the main topic of this publication.
\end{abstract}

\section{Introduction}

The COVID-19 pandemic affected not only the structure of production and consumption, but also the management of organizations. It required organizational changes and a reexamination of interests and values within the organization. Management models are emerging associated with the new position of the employee in the organization and new principles of communication with clients. There are groups of issues that are important in the formation of new relationships both within the organization and outside it: rethinking values, the emergence of new organizational structures, the development of innovative approaches to collecting and analyzing data [1].

Any organizational changes require significant financial resources, especially if they are associated with the introduction of new technologies (since it becomes simply impossible to work on the old ones). Sarah Nagem in her article "5 business strategies for achieving success during a pandemic" [2] cites the opinions of various experts, which boil down to the following: you cannot reduce costs without taking into account strategic changes, you

*Corresponding author: yampolskaya_do@rudn.ru 
must continue to engage in innovative development, cooperate with the company's customers and keep keep them up to date, look for optimal ways to cut costs and ... stay calm.

The COVID-19 pandemic has changed the direction of social and economic life. In the social sphere, this is the strengthening of individualism and self-sufficiency, the manifestation of "discrete" thinking, when, for example, instead of dialogue, you can simply "press the button" and not bother with arguments if you don't like what your opponent says. In the economic sphere, the slogan "increasing efficiency and reducing costs" prevails. Many traditional industries are facing declining consumption and are forced to look for ways to maintain financial sustainability.

The new conditions in which many territorial and industry associations find themselves stimulate the search and development of new technologies. The concept of the 4th technological revolution has appeared, which presupposes (like any revolution) a radical change in all processes and technologies. Almost all of these technologies are in the field of digitalization. The pandemic has accelerated digitalization. If we consider the development of companies as participants in the technological revolution, then there are two main directions that need to be radically changed.

The first would be personnel management problems, especially outside of state capital and major cities. The impact of the pandemic on the internal environment of companies seems to have changed the scope of management. Traditional management functions (planning, organization, motivation and control) had to be adjusted severely to be carried out in a "distant mode". For example, imagine a boss who brings up a negligent subordinate on Zoom using foul or negative language. The subordinate can simply turn off the sound and the whole "educational" process will have no effect. On the other hand, teleworking leads to a "burnout" effect, since you cannot get up and go home - one is at work non-stop. And there are a lot of such examples appearing on a daily basis in the management knowledge base today.

Digitalization is in many ways a transformation of governance. Management moves to a new level, with a great decrease of the emotional component. It becomes more formal and deterministic. The main challenge facing many companies during a pandemic is resilience. According to many management specialists, the main element of sustainability is the organization's personnel and relationships in the new conditions of remote and in-person work. Think about how to maintain and develop the company's most important asset: employees and customer relationships. [3].

The management features that appear during a pandemic include:

1. the speed of decision-making, which technically depends on the automation of workflow and the communicating procedures with employees;

2. organization of online procedures for interviewing employees in various areas, which are more formal in nature - the procedure for relationships becomes more formal, while interpersonal relationships are weakening;

3. tracking contacts of work with clients and highlighting the so-called "points of contact";

4. stimulating employees to work more creatively (real-time employee experience or employee engagement);

5. the control functions change, the emotionality and subjectivity of the assessment disappears;

6. redevelopment of assessing criteria the work done by personnel.

Another problem is the introduction of new technologies that are associated with the processes of active digitalization of business processes. The list of these technologies is well known: robot process automatization, Big Data, chat bots, virtual and augmented reality (VR / AR), optical recognition, artificial intelligence (AI), Internet of things (IoT), 
blockchain. Companies actively implement digitalization of various processes once they understand what benefits it will bring in terms of cost reduction and in terms of creating added value for the client (for which the client will agree to pay more). The process of creating and implementing these technologies is always associated with providing added value and ensuring financial stability. The development of e-commerce as a comprehensive tool for sustainability and business development in the new conditions is possible only with the use of digital technologies, the development of which was accelerated by the COVID19 pandemic.

\section{Research results}

\subsection{Digitalization in Russian regional companies: current situation and prospects}

Digitalization of technological and business processes involves work in the following areas. First of all, it is the operational efficiency associated with production technology. As mentioned above, the introduction of digital technologies should be justified by obtaining added value and increasing the efficiency of the company. Russian regional companies began to implement digital technologies even before the COVID-19 pandemic. The digitalization leaders are telecommunications companies, IT, banks and financial institutions, retail and oil and gas industry.

In 2019, a Russian partner of the consulting company KPMG conducted a study aimed at studying the use of digital technologies in Russian companies. According to the study, the majority of companies $(77 \%)$ expect digitalization to increase the productivity and efficiency of management processes.

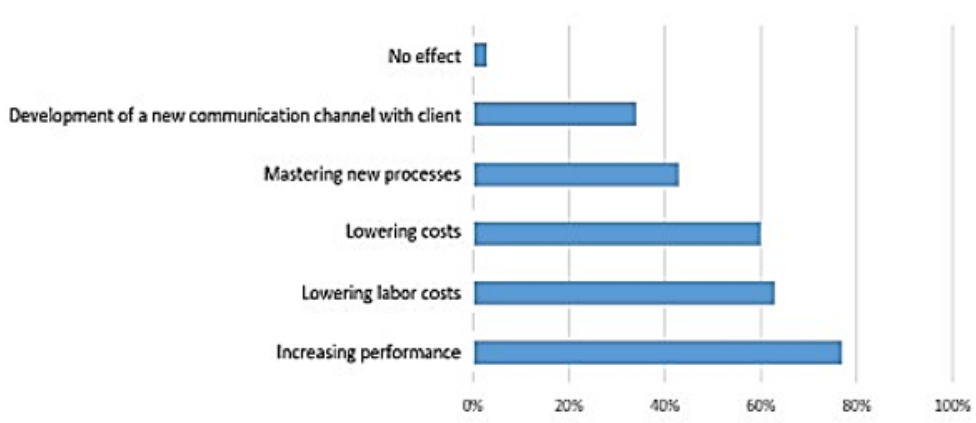

Fig. 1. The effect of using digitalization in companies.

Source: Digital technologies in Russian companies. Study results. KPMG, 2019

Figure 1 shows the benefits that companies have already seen from digital adoption. The first three positions are related to the economic performance of companies: increased productivity, reduced labor costs, and reduced costs. All this leads to a reduction in the cost of production and an increase in price stability. The effect of mastering new processes is associated with an increase in the efficiency of personnel and the speed of adoption of a new technological process. All this is also reflected in the cost price. The fifth point was the improvement of work with clients. This position characterizes the company's interest in 
developing demand for its products. Attracting and retaining customers, increasing the speed of their service, etc. create additional competitive advantages for companies. Although the absolute cost will increase in this case. And only about $4 \%$ of respondents answered that they did not notice any effect.

The popularity of technology shows the directions of organizational changes that are most in demand: cost reduction and optimization of work with clients. The first change in terms of cost savings is staff reduction and / or more efficient work. The introduction of robots allows, on average, to replace 4.5 employees and simplifies the personnel management process. Another popular area is analyzing the state of the company and planning work with clients. To optimize these processes, predictive analytics tools are used, which allow not only highlighting target groups of consumers, but also making the most balanced commercial offer in terms of price and quality. In this regard, big data tools and chat bots have become the technology leaders. Figure 2 shows a rating of technologies that are already being used by Russian companies. In terms of technology, the most popular are big data tools $(68 \%)$, robots $(50 \%)$, and chatbots $(51 \%)$. [4].

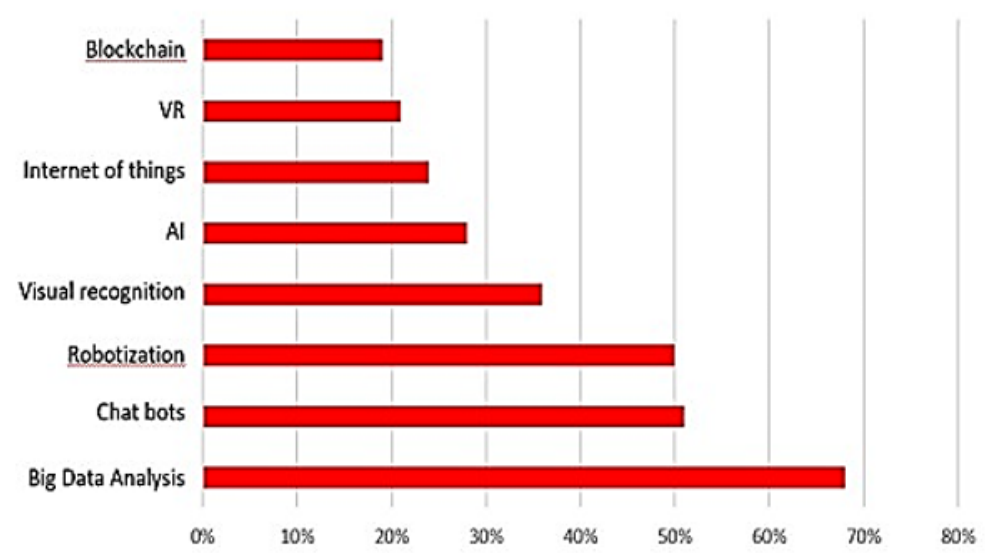

Fig. 2. Technologies used by Russian companies

Information source: Digital technologies in Russian companies. Study results. KPMG,2019.

What trends are observed in Russian business during the pandemic? Let us consider the main directions of the introduction of digital technologies in the Russian Federation during the pandemic (2019 - 20 years) [5]. The priorities remain the same as before the pandemic: developing technologies that reduce labor costs and open up new channels of interaction with the customer / supplier, i.e. the processes of cost reduction and demand generation are relevant [6]. Optimization of business processes can be considered both in the economic context and in the aspect of organizational changes.

The introduction of major innovations requires significant funds and retraining of personnel. The theory and practice of organizational change in companies tells us that the transition to new technologies is very often impeded by technical personnel (middle managers - key performers), who must change their skills and improve their knowledge. It is difficult to motivate experienced workers. "Old" and "new" experience collide. For example, a salesperson who has good connections and contacts with consumers will not want to master predictive analytics techniques. Even without her, he communicates well 
with customers and sales are going well. Analytical conclusions, which will be sent to him by experts in the field of working with big data, he will consider as superfluous information. Therefore, the introduction of new technologies occurs mainly in stages. The process begins with the improvement of individual operations and, as you master them, moves on. In the conditions of most enterprises, the digitalization process can be called evolutionary. Revolutionary reorganization actions carry great risks, both in the field of finance and in personnel policy. Difficulties can arise from a legal point of view, when innovative processes are introduced in which regulations have not been developed and the regulatory authorities simply cannot check it due to the lack of certification. From the point of view of organizational processes, in general, innovation processes are not separated into a separate function or a separate subdivision, which confirms the model of implementation of innovations "upwards".

The development of digitalization has its positive aspects and problem areas. Digital technologies can be applied in any field of activity. Digitalization leads to business diversification and the entry of non-core companies into the market, which intensifies competition and the struggle for a buyer. For example, transportation and delivery, whose role has grown significantly during the pandemic, can now be handled by completely noncore companies. An example is the diversification of Yandex, which delivers everything from food to passengers to the airport. The largest financial organization in Russia, Sberbank, has organized its own service for the delivery of goods from retail and parcels to the population. Russian Post has opened its own bank. There are trends in business merger processing centers and their management. The regional companies inevitably would follow these trends.

Despite the fact that digitalization is announced as a strategic direction for business development, the importance of applied technologies and real assets still remains higher. The use of new digital technologies brings added value, which is significantly higher in service organizations than in real manufacturing companies. The tasks of digitalization in production are the financial sustainability of the enterprise and the development of skills for mastering new technologies, i.e. management tasks. The use of new technologies develops the creativity and communication skills of employees during the period of work remotely. The processes of knowledge exchange, learning and joint activities are also being developed to achieve the common goals of the organization [7].

\section{$3 \mathrm{E}-c o m m e r c e$ as the main engine of digital technologies}

One of the main tasks of any commercial organization is to maintain and develop demand for its products. This requires offering consumers "convenient" products and building appropriate communication channels. E-commerce is now the main engine driving the growth of innovation and digital technology. Digital technologies are divided into two areas: digital products and digital channels used by consumers. 


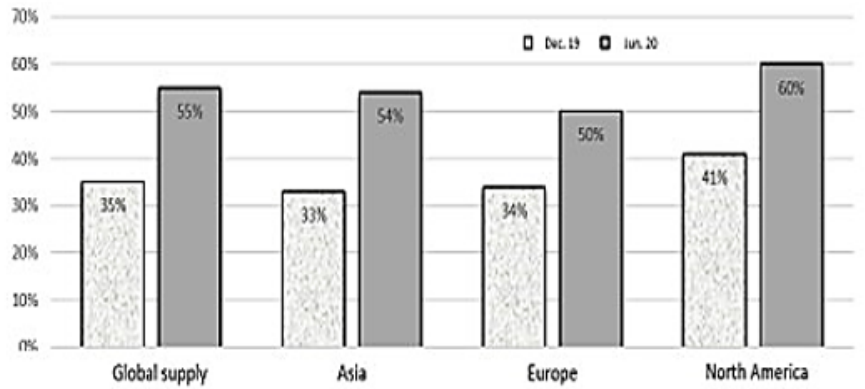

Fig. 3. Relative share of products / services that are partially or fully digital.

Source: How COVID-19 has pushed companies over the technology tipping point - and transformed business forever. Survey. McKinsey \& Company. https://www.mckinsey.com/b.

Figure 3 shows data from McKinsey's research on how digital product offerings have changed over the six months of the pandemic, from December 2019 to June 2020. In almost all regions, this supply has increased in leaps and bounds. According to the same study, purchasing behavior has also changed in leaps and bounds. Shoppers all over the world are embracing digital communications - consumers have abruptly shifted to online channels. The study also showed that the degree of digitalization of the supply in different industries is different. Manufacturing businesses have a relatively low percentage of digital products, while healthcare and pharmaceuticals, financial services, and the like, companies report nearly double the growth of companies like CPG (consumer packaging goods).

The SARS-CoV-2 pandemic and the measures taken by governments in many countries to contain the infection have accelerated the growth trend of e-commerce and prompted many consumers to shop online for the first time. For example, based on an analysis of 1.4 billion banking transactions in Spain since 2019, online purchases are up 22\%, up 7\% from before lockdown. Opinions vary as to the sustainability of this growth following the lifting of the stringent restrictive measures, however, e-commerce can be expected to maintain its momentum, given the trend observed before the pandemic. [8].

Recently, the term "mobile commerce" has appeared. It can be defined as digital trading using applications on mobile devices (smartphones and tablets). The availability of mobile devices is a key driving force in the development of the digital economy. In developed countries in Europe and the United States, about 70\% of B2C e-commerce transactions take place through mobile smartphones. China and India are the world leaders in the size of the smartphone market in the world, surpassing the United States in 2019. Smartphones and social media are indispensable elements of e-commerce development, and the availability of 4G / $5 \mathrm{G}$ services and low-cost tariff plans accelerates the growth of e-commerce.

The fastest growing segment of the Internet is the number of users of mobile social networks such as WhatsApp, Telegram, Twitter, Facebook, WeChat. The integration of social media and e-commerce forms social commerce. The growth rate of social commerce is expected to accelerate over the next 5 years, and it will occupy over a quarter of the ecommerce market. For example, in India alone there are about 310 million active users of social networks, including 59.6 million unique Facebook users and 200 million. active WhatsApp users per month.

The number of Internet users in Russia totals almost 97 million. people with a 
penetration index of $78 \%$. The audience of the mobile Internet in the Russian Federation totals $85.2 \mathrm{mln}$. users, the number of smartphone holders in 2020 reached 106.23 million. people [9]. The share of e-commerce in GDP is $1.3 \%$, and the market volume reached 30.6 billion. dollars in 2019. Online sales to the end consumer (B2C) amounted to 24.9 billion. dollars, which corresponds to an increase of $39 \%$ in orders and $24 \%$ in money turnover [10]. 30\% of digital purchases are made using mobile devices ( $\$ 9.2$ billion) [11]. The online market in Russia last year amounted to 23 billion rubles, while the entire food market amounted to 15 trillion. rubles. Expected in 2021 about 40 trillion rubles.

Technologies for digital marketing, electronic data exchange and automated collection of such data, processing of online transactions, logistics management systems are essential conditions for the growth of e-commerce. The focus should be on the aspect of effective innovation management. Automation of the processes of selling goods and services is becoming a tool for attracting customers. Ecosystems are being actively developed to provide basic needs in one place. Also, services are linked in time and, using artificial intelligence systems, the problem of reducing the choice is solved.

Ecosystems can be classified as global trends in digital commerce. Sberbank, with its recent rebranding into Sberbank, VK and Yandex, is a good example of the formation of a successful brand ecosystem. Sberbank and Yandex combine such components as virtual voice assistants Salyut and Alisa, respectively, streaming services Okko and Kinopoisk, music and podcast service SberSvuk and Yandex Music and complex B2B solutions. Both brands offer their users a comprehensive subscription to all digital services, including music and video services, delivery of food and goods from the store, taxi and delivery services, car sharing and the Dark Store format (only from Yandex). The latter service belongs to the food delivery market, which will drive e-commerce in 2020 and 2021, with projected growth rates of $80 \%$ and $50 \%$, respectively [12]. VK is the most popular social network in Russia (market share - 30.3\%). Created within the brand, the VK ecosystem is also integrated with many companies providing various services and services. It is worth noting that, by analogy with WeChat in China, the company began transforming its mobile application into Super-App, which already contains many mini-versions of its services (Yula, Citymobil) and third-party applications (AliExpress Russia).

The Yula $\mathrm{C} 2 \mathrm{C}$ regional platform is also part of the $\mathrm{VK}$ ecosystem. The total number of sellers on $\mathrm{C} 2 \mathrm{C}$ channels is 13.9 million. people, the number of sellers - 11.8 million. The total market volume in 2019 reached 568 billion rubles from 117 million rubles. sales. The leader of the private trading market is the Avito platform, where 2/3 of all transactions are made. In the first half of 2019 alone, logistics companies delivered 218 million orders made in online stores by customers. The most common way to pay for an online order is with a debit card (53.3\%); 65\% upon advance payment, 47\% upon receipt. The most common types of delivery are self-pickup (69\%), courier delivery (40\%) and parcel terminals $(20 \%)$. The volume of the market for cross-border online purchases in 2019 amounted to 5 billion dollars (1\% of retail sales in the country), which is the 6th indicator in the world [13].

As you can see from these examples, digital technologies collected in customer service ecosystems are the main trend in the development of communication between companies and customers. Leading companies are developing business management models that include elements of internal organization, production, service and communication services to customers.

\section{Conclusion}

The Covid-19 pandemic has shifted the focus to finding the best ways to manage an organization and communicate with customers using digital technologies. E-commerce is, in fact, becoming a new form of communication between companies and their customers. 
Global brands are going through the process of digital transformation in a standard mode, using technologies and innovations of the digital economy for this. The development of the digital economy is expressed in the increased use of such innovations as Data Analytics, Artificial Intelligence, which have become widespread in voice assistants. They, in turn, are often used in conjunction with the Internet of Things and the Robotization process, as well as the practical use of drones and virtual reality (VR). Digital platforms are developing, such as "Facebook", "Amazon", "AliBaba", operating in the framework of e-commerce.

From the point of view of optimizing the management processes of companies, digital technologies make it possible to reduce operating and overhead costs, reduce costs, increase manageability, speed up the solution of R\&D tasks, and simplify business diversification. The complexity of the implementation of digital technologies in the management process is also associated with the increased importance of control over the activities of personnel and their communication with customers. Formalization and individualization of decision making is increasing. The disunity of the team, which works remotely, leads to emotional burnout of employees. And this becomes a problem for the management of the company.

New technologies make it possible to provide the client with new opportunities in solving his problems. Here we can speak about solving problems, not about a "simple" purchase. From the point of view of customer service, digital technologies increase the security and agility of processes, inspire confidence in automated algorithms (decreasing so-called "human factor"), individualization (segmentation) of offers increases, new business models are developed (example of CRM). In conclusion, I would like to emphasize that with all the positive aspects of the introduction of digital technologies, it is not yet entirely clear how this will affect the social life of a person and society.

\section{References}

1. J. M. Amis, R. Greenwood, J. of Management Study

2. N. Sarah, 5 business strategies for success during the pandemic

3. Leading and Managing a Company During the COVID-19 Pandemic (Walden University, 2021)

4. Digital technologies in Russian companies. Results of the study. Survey (2019)

5. Research on digitalization and innovative openness of Russian enterprises. Analytical report. KPMG 2020 (2020)

6. KPMG - media portal, https://mustread.kpmg.ru/

7. The Fourth Industrial Revolution Targets the development of industrial technologies and innovations (2019)

8. Effects of e-commerce on prices and business competition (Bancode Espana, 2020)

9. Ranking of the number of smartphone users in Europe by country 2020 (2020)

10. E-commerce in Russia Data Insight (2019)

11. The Growth of Russia's E-commerce Market. Data Insight (2020)

12. Results of the year: RAEC data (2019)

13. Russian e-commerce market: results of 2019, trends of 2020 (HSE, 2020)

14. How COVID-19 has pushed companies over the technology tipping point-and transformed business forever. Survey (McKinsey \& Company, 2020)

15. KPMG media portal. Technologies, Interviews 